\title{
Vibratory stimulation increase the electro-cutaneous sensory detection and pain thresholds in women but not in men Lisbeth Dahlin ${ }^{1}$, Irene Lund ${ }^{2}$, Thomas Lundeberg ${ }^{3}$ and Carl Molander*1,4
}

\begin{abstract}
Address: ${ }^{1}$ Department of Public Health Sciences, division of Rehabilitation Medicine, Karolinska Institutet, SE 17177 Stockholm, Sweden, 2Department of Physiology and Pharmacology, Karolinska Institutet, SE-171 77 Stockholm, Sweden, ${ }^{3}$ Rehabilitation Medicine University Clinic Stockholm, Danderyds Hospital, SE-182 88 Stockholm, Sweden and ${ }^{4}$ Department of Rehabilitation Medicine, Uppsala University Hospital. SE75185 Uppsala, Sweden
\end{abstract}

Email: Lisbeth Dahlin - Lisbeth.Dahlin@ki.se; Irene Lund - Irene.Lund@ki.se; Thomas Lundeberg - thomas.lundeberg@ds.se; Carl Molander* - carl.molander@ki.se

* Corresponding author

\section{Published: 23 May 2006}

BMC Complementary and Alternative Medicine 2006, 6:20 doi:I0.1 186/1472-6882-6-20

This article is available from: http://www.biomedcentral.com/I472-6882/6/20

(C) 2006 Dahlin et al; licensee BioMed Central Ltd.

This is an Open Access article distributed under the terms of the Creative Commons Attribution License (http://creativecommons.org/licenses/by/2.0), which permits unrestricted use, distribution, and reproduction in any medium, provided the original work is properly cited.
Received: 13 December 2005

Accepted: 23 May 2006

\begin{abstract}
Background: Vibratory stimulation is a potential method for the treatment of pain.

Methods: The effect of vibration on the forearm on detection (DT) and pain thresholds (PT) induced by electro-cutaneous stimulation were investigated in healthy male and female volunteers.

Results: Women have lower baseline detection and pain thresholds as compared to men. Furthermore, women but not men report increased detection and pain thresholds after vibratory stimulation.

Conclusion: Our findings indicate the potential usefulness of vibratory stimulation for pain treatment, and that gender differences should be considered in future evaluation of the method.
\end{abstract}

\section{Background}

Vibratory stimulation is one of several non-pharmacological techniques used to reduce pain. The effects of vibration on pain has been reported in both clinical [1-8] and experimental [9-16] settings. Activation of the mechanical transient receptors is likely to be important (for review see [17]), but contribution of other more slowly adapting receptors can not be excluded [3]. Vibration activates both superficial and deeply located receptors $[11,18,19]$. The subsequent afferent activity in myelinated sensory axons may interact with nociceptive processing at several levels of the nervous system, including the spinal cord. One of the effects is a long lasting elevation of the pain threshold (PT) $[9,14-16]$.
A number of experimental, clinical and epidemiological studies have shown that men and women experience pain differently; for review see ref. $[20,21]$. In healthy volunteers, women often report lower thresholds and tolerance to painful stimuli compared to men [21-24]. It has been suggested the gender differences are related partly to the mode of painful stimulation and pain induction method (frequency, duration, size and location) [23], the manner of presentation $[20,24]$, but also to gender-related physiological differences $[20,21,23,25,26]$. In experimentally induced pain, women seem to be more sensitive to painful mechanical pressure, electrical stimulation and ischemic pain compared to men [22-24,27]. There are yet no reports on possible gender-related threshold responses to vibration stimulation. 
Table I: Assessed levels of detection and pain thresholds in response to vibratory stimulation to one forearm. Descriptive data, showing Pain matcher values as median value and range ( $\min$ to max, numerical cut-off 0-99).

\begin{tabular}{|c|c|c|c|c|c|c|c|c|}
\hline & Before & & During & & Immediately afte & & 10 minutes after & \\
\hline & Women, $n=29$ & men, $n=27$ & Women, $n=29$ & men, $n=27$ & women, $n=29$ & men, $\mathrm{n}=27$ & women, $n=27$ & men, $n=24$ \\
\hline $\begin{array}{l}\text { Detection } \\
\text { threshold }\end{array}$ & 3 (I to 8$)$ & 5 (I to 9$)$ & $4(1$ to 8$)$ & 5 (2 to 8$)$ & 4 (2 to 9$)$ & 5 (I to 9) & $4(2$ to 7$)$ & 5 (2 to 8$)$ \\
\hline Pain threshold & 12 (5 to 24$)$ & I5 (5 to 7I) & $16(6$ to 30$)$ & 17 (7 to 99$)$ & 15 (7 to 24$)$ & 18 (7 to 93$)$ & 12 (6 to 27$)$ & 19 (8 to 93$)$ \\
\hline
\end{tabular}

The aim of the present study was to evaluate the effect of vibratory stimulation on electro-cutaneous detection threshold and pain threshold levels in healthy volunteers taking also the possible influence of gender into account.

\section{Methods}

The experimental subjects were healthy student volunteers recruited from the physiotherapy programme at the Karolinska Institute. They were informed of the purpose and non-invasive experimental procedures before the experiments commenced and that they could leave at any time. The study was approved by the Ethic Committee of the Karolinska Hospital (dnr. 01-169).

\section{Assessment of detection and pain thresholds}

The threshold assessment procedure includes non-invasive electrocutaneous stimulation of the skin of the thumb and forefinger of one hand by pressing the electrodes of the electrical stimulation unit. When reaching the respective threshold level the subjects release there fingers from the electrodes. The detection threshold (DT) was defined as the first pricking sensation and the pain threshold (PT) when the pricking sensation was altered to the first sensation of pain.

The threshold values at the respective levels were automatically recorded immediately when the fingers were released from the electrodes, but in that moment not shown to the subjects making them blind to the ongoing assessments.

The threshold assessment unit is controlled by a microprocessor (PainMatcher ${ }^{\circledast}$, Cefar Medical AB, Sweden). The generated current is distributed with a monophasic rectangular pulse of $15 \mathrm{~mA}$ and $10 \mathrm{~Hz}$. The output intensity increases by gradually widening the pulse duration in steps of $4 \mu$ s to a maximum of $396 \mu$ s, i.e. in a total of 99 steps directly related to the output. The maximum electrical charge per pulse is $5.9 \mu \mathrm{C}$. The contact surface area, and hence the resulting current density, is ensured by a certain load of minimum finger pressure against the electrodes. Loads between 0 and $13 \mathrm{k} \Omega$ secured the output of $15 \mathrm{~mA}$. The numerical cut-off range is $0-99$.
Both electrical DTs and PTs were recorded on four occasions separated by 10 minutes: before, during and after vibration stimulation.

\section{Vibratory stimulation}

The vibratory stimulation (Vitamed, Germany) was applied with a rectangular probe of $13 \times 20 \mathrm{~cm}$ to the dorsal aspect of the forearm, covering the dermatomes C5-8, with $3000 \mathrm{~Hz}$, and a constant and moderate pressure for 20 minutes. The therapist was well-known to the experimental subjects.

\section{Statistics}

The mean value and standard deviation (SD) were calculated for age. The threshold assessments were regarded as subjective estimations and the produced threshold data as ordinal data, here presented as the median and range (minimum to maximum) for the numerical units of the PainMatcher (PM) values [28,29].

The proportions of subjects with increased, unchanged, and decreased threshold values on the second occasion were calculated. The hypotheses of no change in threshold assessments between before and after vibration were analyzed by the non-parametric sign test. Mann Whitney Utest was used to analyse gender differences. A p-value less than 0.05 was regarded as significant.

\section{Results}

Twenty-nine women (mean age 27.7, SD 6.8) and 27 men (mean age 27.7, SD 6.9) participated in this study. The assessed levels of DT and PT levels are shown in table 1.

Immediately after the vibration, the DT were increased compared to before vibration in 16 of the 29 women (55\%), unchanged in $8(28 \%)$, and decreased in $5(17 \%)$, $\mathrm{p}=0.03$. In men, the DT was increased in 12 of the 27 men $(44 \%)$, unchanged in $10(37 \%)$, and decreased in 5 $(19 \%), p=0.21$, fig 1 .

The PT was increased after vibration in 22 of the 29 women $(76 \%)$, unchanged in $4(14 \%)$, and decreased in $3(10 \%), p=0.005$. For the men the pain threshold level was increased in 13 of the 27 men (48\%), unchanged in 4 $(15 \%)$ and, decreased in $10(37 \%), p=0.23$, fig. 2 . 

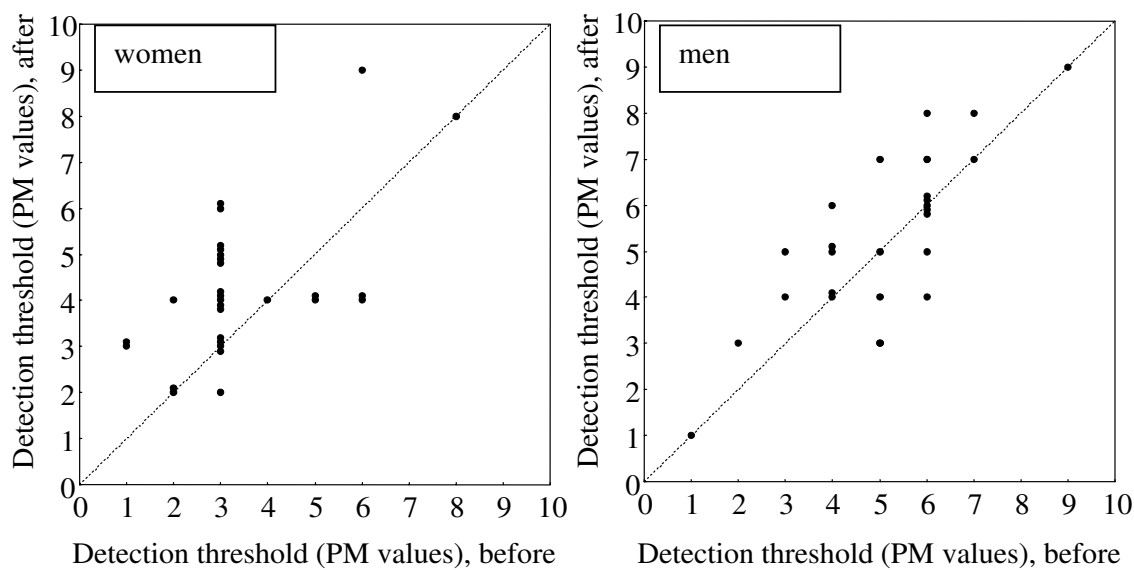

\section{Figure I}

Detection threshold. Changes in assessed DT in women (left) and men (right). PM = pain matcher.

By comparing the respective threshold level in the women and men before the vibration stimulation, it was found that both the detection and pain thresholds were significantly lower in women as compared to men, $\mathrm{p}=0.0002$ and $\mathrm{p}=0.007$ respectively. After the vibratory stimulation the detection threshold levels were still lower in women than in men, $\mathrm{p}=0.008$. Despite a larger number of men than women with decreased PT after vibration, this difference was not significant $(p=0.07)$, fig 3 .

\section{Discussion}

\section{Technical considerations}

Higher baseline DTs and PTs to electrical stimulation in men compared to women seems to be a frequent finding in previous studies, e.g. $[22,24]$.

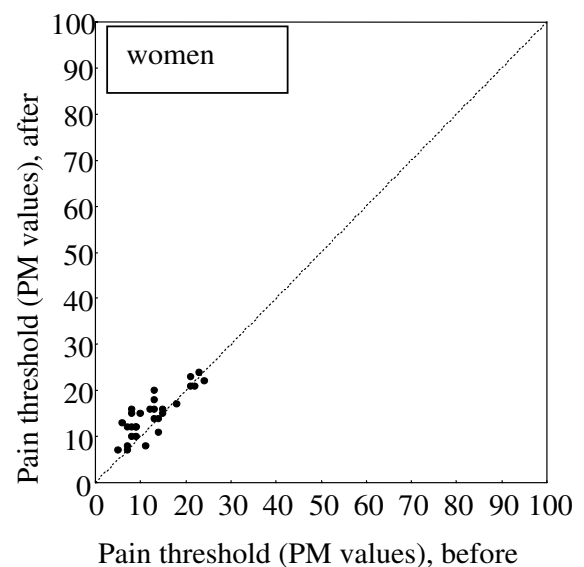

Previous studies have shown that in order to get optimal pain relief, the best site to apply the vibration probe is either in the area of pain or in dermatomes no more than two segmental levels from the pain $[1,3,10,30]$, or in the same dermatome on the contralateral side [10], or in a trigger point outside the painful area using moderate pressure [30]. Vibration distal to the site of threshold measurement also seems to be more effective, at least during the stimulation [31]. Furthermore, findings in a previous report indicate that a larger size of the stimulus probe results in more pain relief [3]. In this study, the vibration was applied across up to four dermatomes, proximal to and in the same arm as the test stimulus, and the vibratory probe was relatively large $(13 \times 20 \mathrm{~cm})$ with the aim to cover a reasonably large area. The 20 minutes used as standard application duration in this study is within the

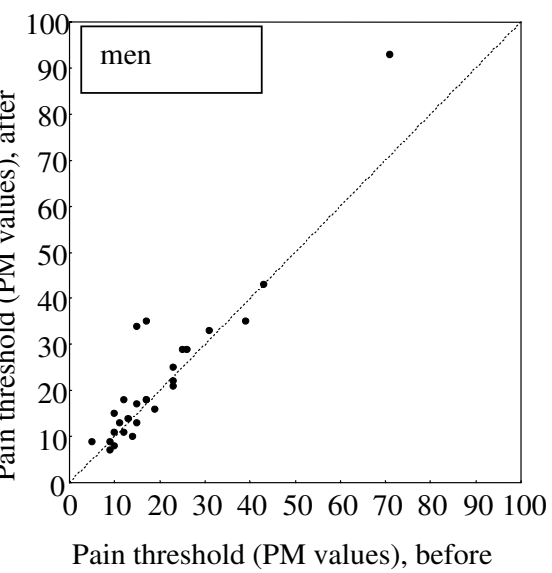

Figure 2

Pain threshold. Changes in assessed PT in women (left) and men (right). PM = pain matcher. 

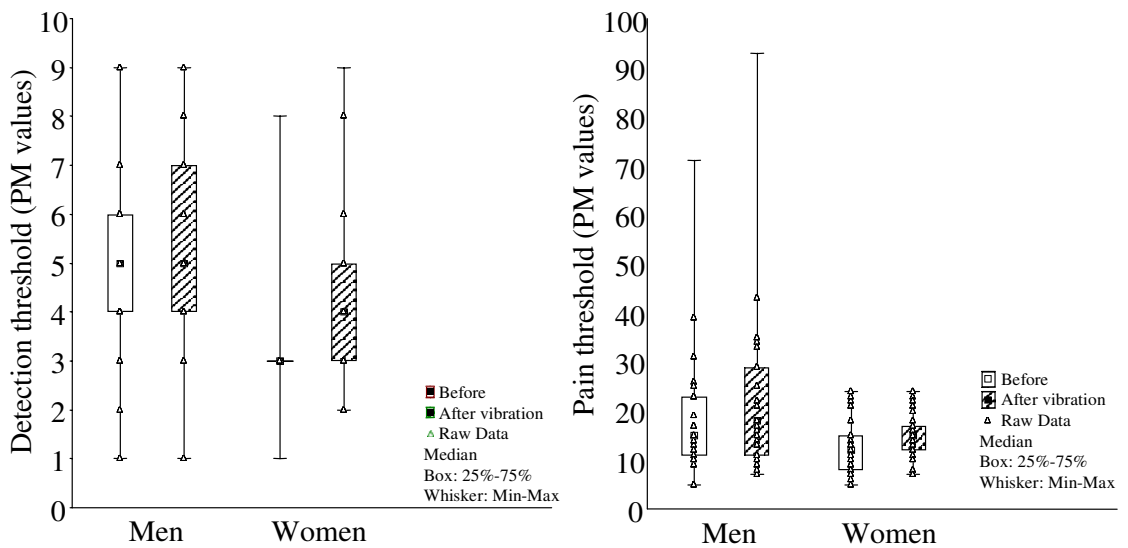

\section{Figure 3}

Gender differences. Changes related to gender in assessed DT (left) and PT (right). PM = pain matcher.

time interval used in previous studies, and was shown to be the shortest duration to elicit maximal pain relief for the most patients in a group with myalgia [6], but the most efficient application time for various pain states seems to be unknown. It could be that a longer application time than 20 minutes would have been more effective. Another factor which could be of importance is cyclic variation in thresholds to pain stimulations linked to the menstrual cycle [32]. We did not include this variable in the present study.

\section{Effects of vibratory stimulation}

The finding of this study that vibration may increase the threshold for experimentally induced pain is in accordance with earlier findings $[10,15,16]$. It is unclear how afferent signals elicited by vibration interfere with central transmission of nociceptive stimuli even though there are indications of mechanisms that include purinergic mechanisms [33,34], lowering of spinal substance P [35], but not, however, ligands to naloxone sensitive $\mu$-opioid receptors [36,37].

Clinically, the effect of vibration stimulation in patients with different pain states varies between studies. Some demonstrated a pain lowering effect $[1,3,10,30]$ whereas others were unable to show a statistically significant effect [38,39].

\section{Gender differences}

The reason why women tend to have lower thresholds to some types of sensory stimulation including painful stimuli is obscure. The sensitivity to vibration as such does not appear to be different between men and women [40], indicating that differences in the intensity of the afferent signal was not the cause.
Another possibility is gender related differences in temporal summation. Temporal summation of painful stimuli has previously been shown to be larger in women $[41,42]$, see however [43]. Whether this is also true for non-painful stimulation does not seem to be known. It could be that longer vibration duration in men would have cancelled out the observed threshold differences between men and women.

Even though gender related differences in pain perception have been reported [24,27], the gender differences appear to be rather small. The differences have been attributed to experimental, social, psychological and physiological factors, including the experimental setup and mode of stimulation, attention, emotional reactions including anxiety, willingness to report pain and gender of experiment assistant, and to catstrophizing $[13,20,23,44]$. Some of the complexity of the issue is also illustrated by the finding that repetitive mechanical painful stimuli were rated equal for the first stimulus, but higher in women than in men for the fifth and tenth stimulus, respectively [41], indicating central mechanisms. Also in line with this, less habituation in women than in men was found after intramuscular glutamate injections [26], and greater temporal summation following repetitive noxious stimulation [42].

\section{Conclusion}

The main results of the present study are firstly that women have lower baseline DTs and PTs to electrical stimulation than men, and secondly that women, but not men, respond with an increase of the DTs and PTs immediately after vibration stimulation. Even though vibration had a statistically significant effect in women, further studies are needed to investigate the effect in a clinical context. 


\section{Competing interests}

The author(s) declare that they have no competing interests.

\section{Authors' contributions}

LD supervised the sensory measurements in participating subjects, collected data and drafted the article. IL performed the statistical analysis, contributed to the writing of the results section, and produced tables and figures. TL conceived of the study, participated in its design and helped to draft the manuscript. CM helped to draft the manuscript, participated in its coordination and final design. All authors read and approved the final manuscript.

\section{Acknowledgements}

This work was supported by grants from Karolinska Institutes foundation and Cefar Medical Inc.

\section{References}

I. Ottoson D, Ekblom A, Hansson P: Vibratory stimulation for the relief of pain of dental origin. Pain 198I, 10:37-45.

2. Ekblom A, Hansson P: Extrasegmental transcutaneous electrical nerve stimulation and mechanical vibratory stimulation as compared to placebo for the relief of acute oro-facial pain. Pain 1985, 23:223-229.

3. Hansson P, Ekblom A: Influence of stimulus frequency and probe size on vibration-induced alleviation of acute orofacial pain. Appl Neurophysiol 1986, 49:155-165.

4. Lundeberg TC: Vibratory stimulation for the alleviation of chronic pain. Acta Physiol Scand Suppl 1983, 523:I-5I.

5. Lundeberg $\mathrm{T}$ : Long-term results of vibratory stimulation as a pain relieving measure for chronic pain. Pain 1984, 20:13-23.

6. Lundeberg T: The pain suppressive effect of vibratory stimulation and transcutaneous electrical nerve stimulation (TENS) as compared to aspirin. Brain Res 1984, 294:20I-209.

7. Lundeberg T, Abrahamsson P, Bondesson L, Haker E: Vibratory stimulation compared to placebo in alleviation of pain. Scand J Rehabil Med 1987, 19:153-158.

8. Roy EA, Hollins M, Maixner W: Reduction of TMD pain by highfrequency vibration: a spatial and temporal analysis. Pain 2003, I $01: 267-274$.

9. Lundeberg T, Abrahamsson P, Bondesson L, Haker E: Effect of vibratory stimulation on experimental and clinical pain. Scand J Rehabil Med 1988, 20:149-159.

10. Yarnitsky D, Kunin M, Brik R, Sprecher E: Vibration reduces thermal pain in adjacent dermatomes. Pain 1997, 69:75-77.

11. Weerakkody NS, Percival P, Hickey MW, Morgan DL, Gregory JE, Canny BJ, Proske U: Effects of local pressure and vibration on muscle pain from eccentric exercise and hypertonic saline. Pain 2003, 105:425-435.

12. Hollins M, Roy EA, Crane SA: Vibratory antinociception: effects of vibration amplitude and frequency. J Pain 2003, 4:38I-39I.

13. Longe SE, Wise R, Bantick S, Lloyd D, Johansen-Berg H, McGlone F, Tracey I: Counter-stimulatory effects on pain perception and processing are significantly altered by attention: an fMRI study. Neuroreport 200I, 12:202I-2025.

14. Pantaleo T, Duranti R, Bellini F: Effects of vibratory stimulation on muscular pain threshold and blink response in human subjects. Pain 1986, 24:239-250.

15. Zoppi M, Voegelin MR, Signorini M, Zamponi A: Pain threshold changes by skin vibratory stimulation in healthy subjects. Acta Physiol Scand 1991, 143:439-443.

16. Kakigi R, Shibasaki $\mathrm{H}$ : Mechanisms of pain relief by vibration and movement. J Neurol Neurosurg Psychiatry 1992, 55:282-286.

17. Willis WD, Coggeshall RE: Sensory mechanisms of the spinal cord. Volume I and 2. 3rd edition. New York, Kluwer academic/Plenum publishers; 2004.
18. Hagbarth KE, Eklund G: Motor effects of muscle vibration in spasticity, rigidity and cerebellar disorders. Electroencephalogr Clin Neurophysiol 1968, 25:407.

19. Ferrington DG, Nail BS, Rowe M: Human tactile detection thresholds: modification by inputs from specific tactile receptor classes. J Physiol 1977, 272:415-433.

20. Berkley KJ: Sex differences in pain. Behav Brain Sci 1997, 20:37I-80; discussion 435-5I3.

21. Rollman GB, Lautenbacher S: Sex differences in musculoskeletal pain. Clin J Pain 200I, 17:20-24.

22. Lautenbacher S, Rollman GB: Sex differences in responsiveness to painful and non-painful stimuli are dependent upon the stimulation method. Pain 1993, 53:255-264.

23. Fillingim RB, Maixner W: Gender differences in the responses to noxious stimuli. Pain Forum 1995, 4:209-221.

24. Riley JL, Robinson ME, Wise EA, Myers CD, Fillingim RB: Sex differences in the perception of noxious experimental stimuli: a meta-analysis. Pain 1998, 74:18I-187.

25. Craft RM, Mogil JS, Aloisi AM: Sex differences in pain and analgesia: the role of gonadal hormones. Eur J Pain 2004, 8:397-4I I.

26. Ge HY, Madeleine P, Arendt-Nielsen L: Gender differences in pain modulation evoked by repeated injections of glutamate into the human trapezius muscle. Pain 2005, I | 3: I 34- I 40.

27. Wise EA, Price DD, Myers CD, Heft MW, Robinson ME: Gender role expectations of pain: relationship to experimental pain perception. Pain 2002, 96:335-342.

28. Svensson E: Concordance between ratings using different scales for the same variable. Stat Med 2000, 19:3483-3496.

29. Lund I, Lundeberg T, Sandberg L, Budh CN, Kowalski J, Svensson E: Lack of interchangeability between visual analogue and verbal rating pain scales: a cross sectional description of pain etiology groups. BMC Med Res Methodol 2005, 5:31.

30. Lundeberg $\mathrm{T}$ : Vibratory stimulation for the alleviation of pain. Am J Chin Med I 984, 1 2:60-70.

31. Sherer CL, Clelland JA, O'Sullivan P, Doleys DM, Canan B: The effect of two sites of high frequency vibration on cutaneous pain threshold. Pain 1986, 25:|33-|38.

32. Riley JL, Robinson ME, Wise EA, Price DD: A meta-analytic review of pain perception across the menstrual cycle. Pain 1999, 8I:225-235

33. De Koninck Y, Henry JL: Peripheral vibration causes an adenosine-mediated postsynaptic inhibitory potential in dorsal horn neurons of the cat spinal cord. Neuroscience 1992, 50:435-443.

34. De Koninck Y, Salter MW, Henry JL: Substance $\mathbf{P}$ released endogenously by high-intensity sensory stimulation potentiates purinergic inhibition of nociceptive dorsal horn neurons induced by peripheral vibration. Neurosci Lett 1994, 176:128-132

35. Guieu R, Tardy-Gervet MF, Giraud P: Substance P-like immunoreactivity and analgesic effects of vibratory stimulation on patients suffering from chronic pain. Can J Neurol Sci 1993, 20:|38-|4|.

36. Lundeberg $\mathrm{T}$ : Naloxone does not reverse the pain-reducing effect of vibratory stimulation. Acta Anaesthesiol Scand 1985, 29:212-216

37. Guieu R, Tardy-Gervet MF, Giraud P: Met-enkephalin and betaendorphin are not involved in the analgesic action of transcutaneous vibratory stimulation. Pain 1992, 48:83-88.

38. Watanabe I, Svensson P, Arendt-Nielsen L: Influence of segmental and extra-segmental conditioning, stimuli on cortical potentials evoked by painful electrical stimulation. Somatosens Mot Res 1999, 16:243-250.

39. Taylor AG, Galper DI, Taylor P, Rice LW, Andersen W, Irvin W, Wang XQ, Harrell FEJ: Effects of adjunctive Swedish massage and vibration therapy on short-term postoperative outcomes: a randomized, controlled trial. J Altern Complement Med 2003, 9:77-89.

40. Liou JT, Lui PW, Lo YL, Liou L, Wang SS, Yuan HB, Chan KH, Lee TY: Normative data of quantitative thermal and vibratory thresholds in normal subjects in Taiwan: gender and age effect. Zhonghua Yi Xue Za Zhi (Taipei) 1999, 62:431-437.

41. Sarlani E, Greenspan JD: Gender differences in temporal summation of mechanically evoked pain. Pain 2002, 97:163-169.

42. Sarlani E, Grace EG, Reynolds MA, Greenspan JD: Sex differences in temporal summation of pain and aftersensations following 
repetitive noxious mechanical stimulation. Pain 2004, 109: II5-123.

43. Nie H, Arendt-Nielsen L, Andersen H, Graven-Nielsen T: Temporal summation of pain evoked by mechanical stimulation in deep and superficial tissue. J Pain 2005, 6:348-355.

44. Levine FM, De Simone LL: The effects of experimenter gender on pain report in male and female subjects. Pain 1991, 44:69-72.

\section{Pre-publication history}

The pre-publication history for this paper can be accessed here:

http://www.biomedcentral.com/1472-6882/6/20/prepub

Publish with Biomed Central and every scientist can read your work free of charge

"BioMed Central will be the most significant development for disseminating the results of biomedical research in our lifetime. "

Sir Paul Nurse, Cancer Research UK

Your research papers will be:

- available free of charge to the entire biomedical community

- peer reviewed and published immediately upon acceptance

- cited in PubMed and archived on PubMed Central

- yours - you keep the copyright

Submit your manuscript here:

http://www.biomedcentral.com/info/publishing_adv.asp 